\title{
ph

\section{Una generación de patrimonialistas. Veinte años de formación en patrimonio: la experiencia del MARPH}

En el curso 1995-96 se puso en marcha el Máster Universitario en Arquitectura y Patrimonio, como título propio de la Universidad de Sevilla y con la colaboración de IAPH. A lo largo de sus veinte años de andadura (que se cumplirán en 2015) esta titulación de postgrado ha sabido adaptar su manifiesto inicial integrando cuestiones como la evolución en la tutela, el manejo de conceptos como los recursos culturales para el desarrollo, la preocupación por el paisaje y la sostenibilidad, los nuevos cambios jurídicos y los patrimonios emergentes, convirtiéndose en uno de los cinco títulos de máster más destacados en España de su especialidad, sobresaliendo del resto por su amplitud en el tratamiento del patrimonio.

Eduardo Mosquera Adell | coordinación académica del MARPH

María Teresa Pérez Cano | coordinación académica del MARPH

José Manuel Aladro Prieto | coordinación académica del MARPH

Lourdes Royo Naranjo | coordinación académica del MARPH

URL de la contribución <www.iaph.es/revistaph/index.php/revistaph/article/view/3547>

El Máster Universitario en Arquitectura y Patrimonio Histórico (MARPH) es una titulación de posgrado que en 2015 cumplirá veinte años desde su diseño y puesta en marcha. Inicialmente se plantearon desde la Administración cultural sendos cursos de protección y de conservación y restauración dirigidos al perfeccionamiento de los titulados, que se sumarían a los cursos heredados de archivística y de documentación.

La Consejería de Cultura apostó por vincularlos a la esfera universitaria y otorgarles el rango de máster ${ }^{1}$. Considerando el Decreto 107/1989, de 16 de mayo, en su artículo segundo, apartado f, trasladó al Instituto Andaluz del Patrimonio Histórico -y éste a su Departamento de Formación- la articulación de los cursos de formación de técnicos y personal especializado en materia de patrimonio histórico.

La participación del Instituto Andaluz de Administración Pública, prevista en dicha disposición, se concretaría mediante la homologación de dichas enseñanzas.

En junio de 1995 se aprueban y firman los respectivos convenios con la Universidad de Sevilla, por los que tres títulos de máster comenzarían a impartirse en el curso siguiente: MARPH, MARCH y MIDUS².
La novedad mayor la trajo el Máster en Arquitectura y Patrimonio Histórico (MARPH), que surge de la fusión de planteamientos de los dos cursos antes citados. Se imparte desde el curso 1995-96 como título propio de la Universidad de Sevilla, siempre en colaboración con el IAPH. La Consejería de Cultura optó por profesores de la Escuela de Arquitectura, una de las profesiones relacionadas con patrimonio que se entendía más necesario vincular a procesos formativos de posgrado en dicha materia. De ahí toma su nombre, y en enero de 1995, José Morales, José Ramón Moreno Pérez, Eduardo Mosquera y María Teresa Pérez Cano redactan el Manifiesto del MARPH, donde se establecieron sus bases: un título de carácter generalista en materia de patrimonio histórico, ligado a la gestión tutelar de los bienes culturales, con apertura a las numerosas disciplinas intervinientes, desarrollado con herramientas docentes que potencian la presencialidad, el aprendizaje basado en la práctica sobre problemas reales de bienes culturales concretos de notoria entidad (de ámbitos urbanos y territoriales) $y$, especialmente, el compromiso individual ante el trabajo colectivo interdisciplinar.

La evolución en la tutela, el manejo de conceptos como los recursos culturales para el desarrollo, la preocupación por el paisaje y la sostenibilidad, los nuevos 
cambios jurídicos y los patrimonios emergentes, se integrarán en las sucesivas ediciones. Entre la segunda y la tercera edición se terminan de dibujar las cuatro prácticas esenciales, dedicadas a valorar y proteger, a dinamizar, a musealizar y a estudiar la materialidad de los respectivos bienes sobre los que se trabaja, de forma que se alimente el Proyecto patrimonial, herramienta experimentada desde el máster para innovación de la gestión tutelar y la concreción de propuestas sobre los potenciales de un territorio cultural concreto. Su aprendizaje caracteriza y completa a esta enseñanza ${ }^{3}$. Para ello el propio profesorado es multidisciplinar. Se nutre del ámbito universitario y de expertos invitados, tanto técnicos pertenecientes a la Administración cultural como profesionales especialistas, formando un colectivo de hasta veinticinco especialidades relacionadas con el Patrimonio.

En la cuarta edición se ofrece a sus estudiantes la opción de seguir un $40 \%$ de su docencia en la sede del Patronato de la Alhambra y Generalife. La importancia del hecho -y su continuidad en el tiempo- proporcionan al MARPH una considerable repercusión social y territorial, gracias a la capacidad del Patronato, su personal, instalaciones y acervo documental.

Fue uno de los primeros títulos en la Universidad de Sevilla con los que se comenzaron los estudios de máster insertos en el Espacio Europeo de Educación Superior. Desde 2006-07, con 60 créditos europeos, se oferta como máster oficial, verificándose en 2010 ante el Ministerio de Educación como máster universitario4. Diversos ajustes en sus materias entre 2006 y 2010 han conducido a su formato actual, que refuerza la tradición académica decantada en torno a 2000, y que incluye la oferta a sus estudiantes de una nueva orientación, la investigadora, que se suma a la profesional con que nació.

\section{Los estudiantes}

Una diversidad en el alumnado ha ayudado a configurar, edición tras edición, una identidad característica del $\mathrm{MARPH}$, en gran medida gracias a un proyecto docente articulado de forma diferenciada y novedosa respecto a otros posgrados en patrimonio, constituyendo toda una

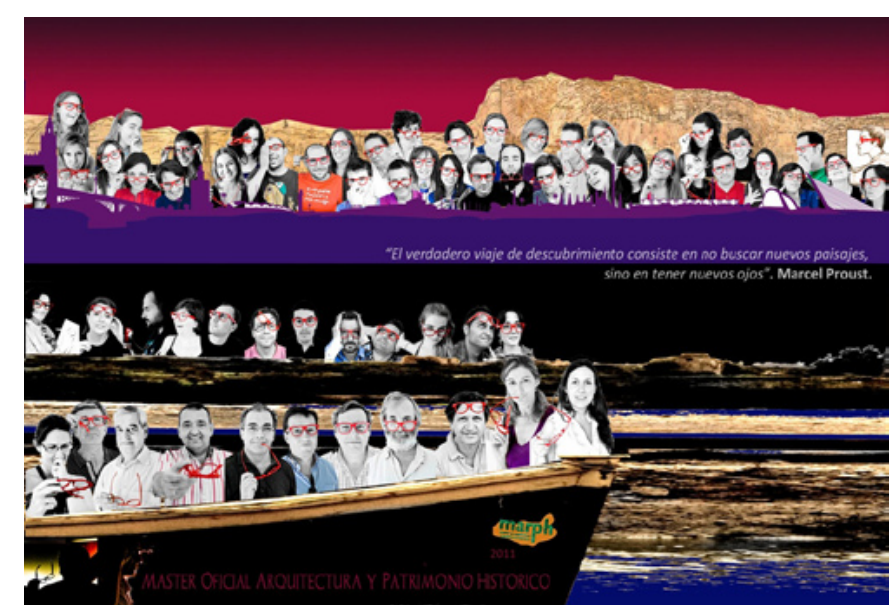

La promoción del marph-11 según los propios estudiantes. Galería de retratos | foto Stefania Scamardi

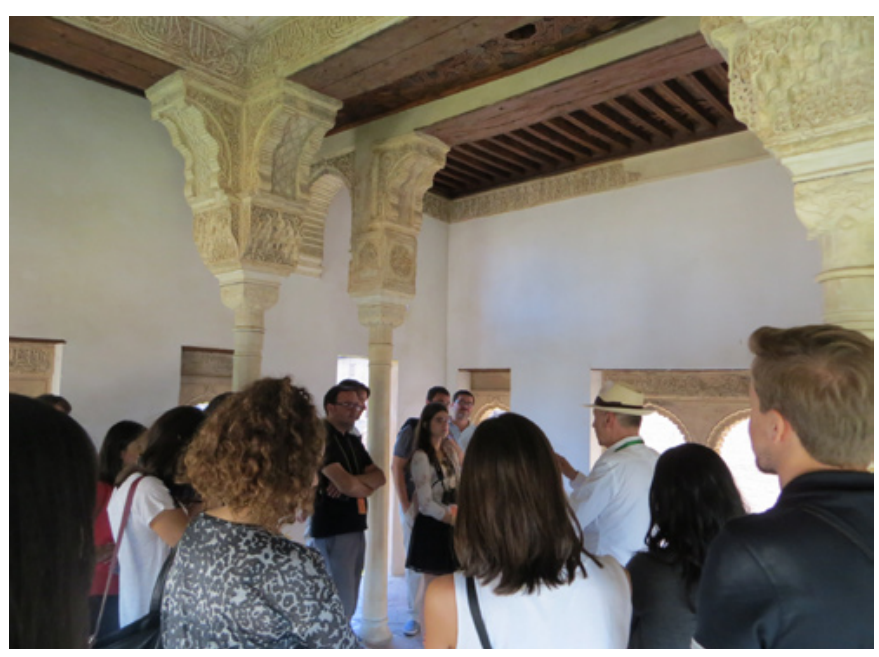

Estudiantes del marph-14 visitando el Peinador de la Reina de La Alhambra | foto autores de la contribución

generación de patrimonialistas. Dirigido tanto a la formación de recién titulados como al perfeccionamiento y reciclaje de todos los profesionales, públicos y privados intervinientes en patrimonio, el MARPH ha desarrollado un modelo docente con una personalidad propia, que posibilita que lo cursen titulados de muy diversos perfiles y procedencias. Se forma en cada promoción un colectivo intergeneracional que se beneficia del trabajo interdisciplinar, abordando tareas especialmente complejas desde el primado de la excelencia, la actualidad y proyección de futuro en el campo de atención a los bienes culturales integrantes del patrimonio histórico. 


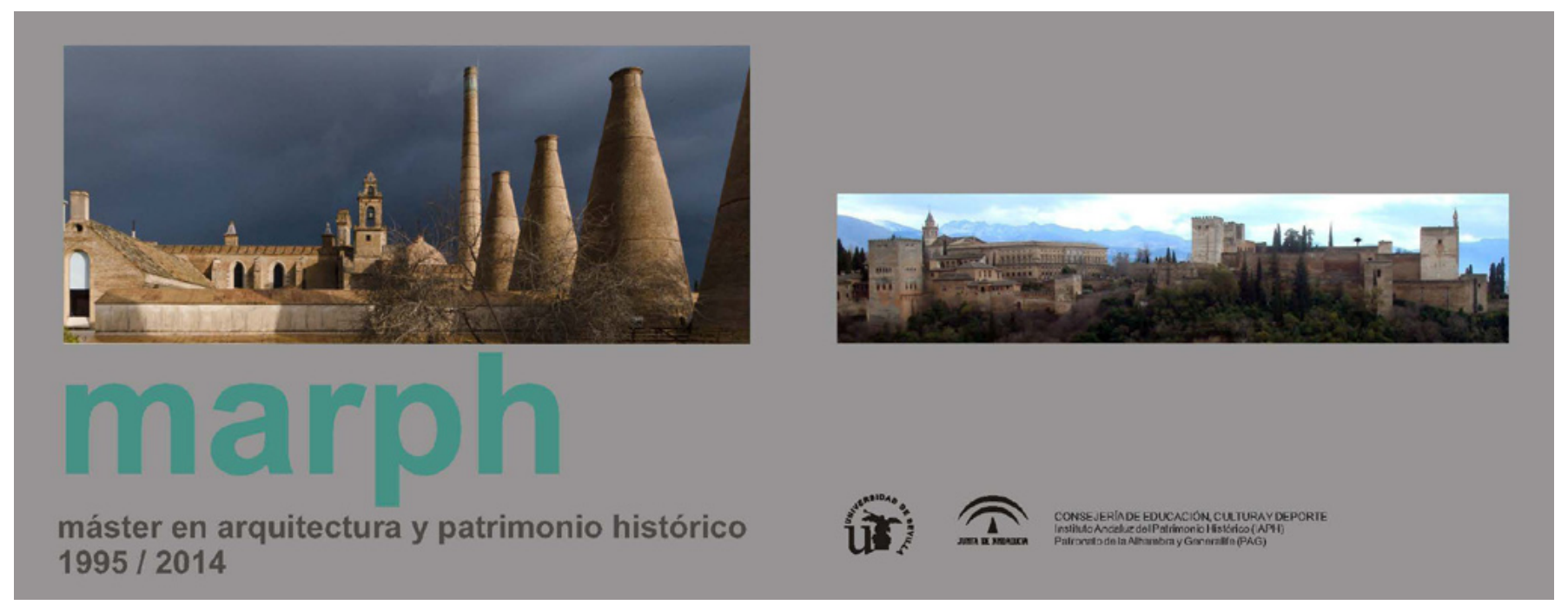

Imagen corporativa del Máster Universitario en Arquitectura y Patrimonio

La procedencia de los estudiantes de este máster abarca -hasta el momento- a titulados de las ocho provincias andaluzas, de catorce comunidades autónomas y ciudades autónomas españolas, sumando estudiantes de veintiuna nacionalidades, procedentes de diez países europeos, uno africano y diez americanos.

\section{Proyección en el mercado laboral}

El Horizonte 2020 -Programa Marco de Investigación e Innovación (2014-2020), establecido por el Consejo Europeo en 2013- fija: "La investigación en el ámbito de las ciencias sociales y las humanidades se integrará plenamente en cada uno de los objetivos específicos de Horizonte 2020. (...) Con este fin, las ciencias sociales y las humanidades se incorporarán también como un elemento esencial de las actividades necesarias para mejorar el liderazgo industrial y para abordar cada uno de esos retos de la sociedad. Para lograrlo se debe, entre otras cosas, (...) investigar y preservar el patrimonio y la riqueza culturales de Europa". La necesidad por tanto de desarrollar una formación de posgrado en este sentido y adecuada a estos requerimientos queda patente.

El perfil de egreso posibilita la profesionalización o perfeccionamiento, vinculada al ámbito de actividad del Patrimonio Histórico. El máster, dentro del marco de la regulación profesional respectiva, prepara a sus estudiantes para desarrollar profesionalmente muy diversos trabajos (informes, estudios, proyectos, planes, gestión administrativa...) para la protección (declaraciones de bienes culturales, inventarios, catálogos, planeamiento urbanístico), conservación, mantenimiento, rehabilitación, restauración, ordenación urbana y del paisaje, de difusión (exposiciones, interpretación cultural, proyectos museográficos, dinamización cultural), etc., etc. del patrimonio histórico y cultural y sus instituciones.

El seguimiento de estancias en instituciones directamente relacionadas con la gestión del patrimonio, la obtención de becas de especialización e inserción profesional y de cooperación internacional son elementos clave. Titulados del MARPH son solicitados para ejercer importantes responsabilidades dentro de la administración cultural y urbanística, en la esfera autonómica, local y estatal ${ }^{5}$. Técnicos y conservadores de patrimonio ejercientes como profesionales libres o como trabajadores por cuenta ajena y en empresas especializadas en el ámbito, integran nuestra nómina de egresados con influyentes realizaciones para nuestro patrimonio ${ }^{6}$.

Numerosos estudiantes del máster han proseguido sus estudios con el Doctorado, tras su paso por el MARPH, alcanzando frecuentemente la Mención Europea o la Internacional ${ }^{7}$, de forma que diversos titulados por este máster son ahora profesores e investigadores de universidades públicas y privadas ${ }^{8}$. 
Su experiencia y productividad se ha mostrado en distintos foros y congresos nacionales e internacionales. Se encuentra reconocido en repetidas ocasiones dentro del ranking del diario El Mundo, como uno de los cinco títulos de máster más destacados en España de su especialidad, sobresaliendo del resto por su amplitud en el tratamiento del patrimonio. Nos encontramos entre la finalización de la decimocuarta edición del MARPH y el comienzo de la decimoquinta, con un proyecto permanentemente actualizado, con alianzas institucionales fortalecidas y que se ha adaptado a las exigencias más recientes en materia formativa y de empleo, mostrando una capacidad nada común de evolucionar. Para ello el propio MARPH ha organizado con el IAPH diversas experiencias formativas de emprendimiento, integración en el tejido profesional e investigador, y de apertura a los nuevos patrimonios y sus nuevos horizontes profesionales.

El patrimonio histórico constituye un sector estratégico para el desarrollo y la innovación en Andalucía. Su adecuada gestión y tutela incide directamente en la calidad de vida de sus ciudades y de sus paisajes; tanto de sus habitantes como de los visitantes, impulsando el turismo cultural e incentivando la investigación para la innovación del ámbito cultural como fuentes de progreso y riqueza. Pero estos intereses lo son también dentro del escenario global europeo y se encuentran de permanente actualidad.

\section{NOTAS}

1. En aquel tiempo el formato máster no tenía carácter oficial, aunque, siguiendo el modelo anglosajón, se había implementado en España dentro de la órbita empresarial y la enseñanza privada. Sin embargo, las universidades públicas se sumaban progresivamente a esta corriente. Bajo el formato de títulos propios, el máster universitario será el título de mayor duración respecto a otros que se ofertaban, como el de experto, cursos de especialización o de formación continua, etc., siguiendo las variantes estatutarias de cada universidad.

2. EI MARCH (Máster en Archivística) es heredero de los cursos de archiveros del IAAP y, asimismo, el MIDUS
(Máster en Información y Documentación) hereda los de documentalistas, con la consiguiente puesta al día. Años más tarde, el IAPH impulsará otros títulos de máster, impartidos tanto por la Universidad de Sevilla como por la Universidad de Granada, dedicados a la Museología y la Gestión Cultural.

3. EI MARPH, ya consolidado, quedó incluido expresamente en el II Plan General de Bienes Culturales, dentro del Programa de Formación y Cualificación de Recursos Humanos, que contó en su momento con aprobación parlamentaria unánime.

4. Se encuentra adscrito a la Escuela Técnica Superior de Arquitectura, si bien entre su profesorado habitual interno se encuentran también docentes de Facultades como Geografía e Historia, Bellas Artes, la Escuela Técnica Superior de Ingeniería de Edificación, etc., pertenecientes a catorce departamentos de la Universidad de Sevilla.

5. Algunos titulados por este máster, de procedencia foránea, trabajan en los ministerios de Cultura y universidades de sus respectivos países.

6. Antiguos alumnos del máster formaron parte del equipo que obtuvo el Premio Nacional de Restauración y Conservación de Bienes Culturales 2006 del Ministerio de Cultura.

7. Doctores egresados del máster han obtenido diversos reconocimientos investigadores: Premio Extraordinario de Doctorado de la Universidad de Sevilla, Premio Fundación Patrimonio Industrial de Andalucía, Premio KORA, Premio Textos de Doctorado de la Universidad de Sevilla (por tesis defendidas en las Universidades de Granada y Sevilla), etc.

8. Ex alumnos del MARPH son profesores, por ejemplo, en las universidades de Sevilla, Granada, Málaga, Pablo de Olavide, Antonio de Nebrija de Madrid, Universidade de Évora o la Escola Universitária das Artes de Coimbra, ambas en Portugal, o la Escuela de Estudios Árabes de Granada, del CSIC. 